\title{
CRIAÇÕES COTIDIANAS PARA ALÉM DOS DISPOSITIVOS DE REGULAÇÃO DA DOCÊNCIA NAS POLÍTICAS DE CURRÍCULO NA ATUALIDADE
}

\author{
Andreia Teixeira Ramos \\ Universidade Federal do Espírito Santo - Ufes, Brasil \\ Renata Rocha \\ Universidade do Estado do Rio de Janeiro - UERJ/FFP, Brasil \\ Elaine Sotero \\ Universidade do Estado do Rio de Janeiro - UERJ/Proped, Brasil
}

\section{Resumo}

Este texto objetiva expor outros modos de criações cotidianas para além dos dispositivos de regulação da docência, presentes nas políticas de currículo na atualidade. Apresentaremos alguns momentos de lutas e resistências históricas com base na educação das relações étnico-raciais, indicando que é preciso e possível caminhar além dos dispositivos de regulação, objetivando se desviar das agendas impostas e propor outros movimentos criadores de resistências. $\mathrm{O}$ artigo tem a base teórico-metodológica acerca das pesquisas nos/dos/com os cotidianos, realizadas pela professora Nilda Alves e seu grupo de pesquisa. Acreditamos que a política está na sociedade e não só nas políticas de currículo oficiais, ou seja, a política está nos cotidianos. Prática é política. Tudo é político. Por isso, consideramos, neste texto, as políticas que acontecem nos cotidianos para além das políticas de currículo oficiais principalmente no momento de crise com os intensos retrocessos e ataques da onda neoconservadora. Nosso interesse está em versar acerca de políticas como práticas coletivas apresentando criações cotidianas realizadas pelos docentes nas diferentes redes educativas, no sentido de criar brechas e escapar dos dispositivos de regulação dessas políticas oficiais de currículo como movimentos de resistência acerca da educação das relações étnico-raciais.

Palavras-chave: Cotidianos; Criações; Currículo; Educação das relações étnico-raciais.

\begin{abstract}
This text aims to expose other modes of everyday creations beyond the regulation devices of teaching, present in curriculum policies today. We will present some moments of struggles and historical based on the educational devices of ethnic-racial relations, indicating that it is necessary, and possible, to go beyond regulatory devices so that we can deviate from the imposed agendas and propose other movements that create resistance. The article has as its theoretical-methodological basis the research in/of/with daily life, carried out by professor Nilda Alves and her research group. We believe that politics is part of society and not just part of official curriculum policies, which means that politics is in everyday life. Practice is politics. Everything is political. Therefore, in this text, we consider the policies that take place in everyday life beyond the official curriculum policies, especially at this moment of crisis with the intense setbacks and attacks of the neoconservative wave. Our interest is approach policies as collective practices, presenting everyday creations made by teachers in different educational networks, in the sense of creating gaps and escaping from the regulatory devices of these official curriculum policies as resistance movements about the education of ethnic-racial relations.
\end{abstract}

Keywords: Everyday creations; Curriculum; Education of ethnic-racial relations; Research with everyday life.

ISSN 1645-1384 (online) www.curriculosemfronteiras.org 


\section{Introdução}

Este texto objetiva expor outros modos de criações cotidianas para além dos dispositivos de regulação da docência, presentes nas políticas de currículo na atualidade. Apresentaremos alguns momentos de lutas e resistências históricas com base nos dispositivos da educação das relações étnico-raciais, indicando que é preciso e possível caminharmos além dos dispositivos de regulação, objetivando "sair da agenda imposta [propondo] movimentos diversos e criadores [de resistência] que possam produzir debates e avanços [nessas] — e em outras - [questões]" como afirma a professora pesquisadora Nilda Alves (2017, p. 01), no texto "Formação de docentes e currículos para além da resistência".

Desse modo, este artigo tem o interesse em problematizar e refletir de modo crítico para além das discussões impostas pelas políticas oficiais de regulação, pois, acreditamos que a política está na sociedade e não só nas políticas de currículo oficiais, ou seja, a política está nos cotidianos. Prática é política. Tudo é político. Por isso, consideramos, neste texto, as políticas que acontecem nos cotidianos para além das políticas de currículo oficiais. Nosso desejo é apresentar criações cotidianas realizadas pelos docentes nas diferentes redes educativas (ALVES, 2019), que acontecem além das pautas oficiais de currículo, principalmente no momento de crise com os intensos retrocessos e ataques da onda neoconservadora.

Assim sendo, desejamos com este artigo versar acerca de políticas como práticas coletivas, em contextos cotidianos, nas múltiplas relações de 'praticantespensantes' nas redes cotidianas de 'conhecimentossignificações', apresentando outros possíveis contextos de formação de professoras e professores e a ideia de 'docentesdiscentes' na contemporaneidade (ALVES, 2010, p. 1195) e seus modos de 'aprenderensinar'. Para tanto, indagamos quais criações cotidianas são realizadas pelos docentes no sentido de criar brechas e escapar dos dispositivos de regulação dessas políticas oficiais de currículo e como esses movimentos de resistência acontecem nas diferentes redes educativas? A partir desse eixo, propomos problematizar essas significações que ocorrem nos cotidianos acerca da atuação dos docentes na escola básica e no ensino superior, expondo outros modos de 'caminharpensarsentirverouvirviver' e entendendo que essas práticas são bricolagens ${ }^{3}$ na criação de currículos, pois "combinam diversos elementos dos cotidianos" de acordo com Renata Rocha e Thamy Lobo (2020, p. 315).

Para isso, este artigo possui quatro momentos-movimentos. No primeiro momento, faremos uma exposição teórico-metodológica acerca das pesquisas nos/dos/com os cotidianos, realizadas pela professora Nilda Alves e seu grupo de pesquisa. No segundo momento, falaremos brevemente acerca das políticas oficiais da educação das relações étnico-raciais. No terceiro momento, apresentaremos experiências das autoras do artigo e de outras professoras com base nas criações cotidianas sobre a educação das relações étnicoraciais. E, no quarto momento, concluímos refletindo acerca da necessidade das práticas sociais como fomentadoras e catalisadoras de políticas cotidianas, o que inclui as políticas curriculares e seus movimentos permanentes nos cotidianos escolares. 


\section{Pesquisas com os cotidianos}

Inicialmente gostaríamos de informar às leitoras e aos leitores o entendimento que fazemos acerca das "políticas", corroborando a compreensão epistemológica que pesquisadoras e pesquisadores da linha teórico-metodológica dos estudos nos/dos/com os cotidianos fazem há algum tempo, sobretudo a partir do pensamento de Nilda Alves (2010) e de trabalhos e publicações de seu grupo de pesquisa (BRANDÃO; MENDONÇA; PAPINI, 2020; MACHADO; MORAIS; TOJA, 2020; MENDONÇA et al., 2020; ROCHA; LOBO, 2020). Esse entendimento orienta toda discussão que se segue e fundamenta o modo como temos criado nossas pesquisas e a produção de conhecimento científico em educação na linha de pesquisa dos cotidianos e das temáticas em currículos.

A autora defende as "políticas como práticas cotidianas [...]" e "necessariamente, sempre coletivas" (ALVES, 2010, p. 1197), entendendo também os cotidianos em sua complexidade, como a vida prática dos seres humanos que neles habitam, "já que [...] ['conhecimentoesignificações '] ${ }^{4}$ são encarnados em nós, nas ações que desenvolvemos nos contextos cotidianos, quanto ao tema "formação de professores"' (ALVES, 2010, p. 1197). Por isso, discutir política é discutir a própria vida, excluindo, dessa maneira, qualquer possibilidade de dizer que os processos educativos estão alheios a ideologias.

A segunda questão a ser colocada é acerca de nossa implicação pessoal-coletiva em tudo que buscamos conhecer e/ou estudar. Portanto, reafirmamos o que já foi dito: as ideologias compõem as pesquisas que temos nos dedicado a fazer, tendo em vista que elas se sustentam nas metodologias da 'conversa' (MATURANA, 1999, 2006) e das narrativas das pessoas com quem conversamos, a quem denotamos chamar de 'praticantespensantes' ${ }^{5}$. A partir disso, importa-nos pensar acerca dos dispositivos de regulação da docência nas políticas curriculares da atualidade e como os docentes têm escapado dessa sistematização.

Outra pertinente questão são as redes educativas a partir das pesquisas nos/dos/com os cotidianos, desenvolvidas pelo grupo de pesquisa de Nilda Alves (2019), as quais têm tornado possível sinalizar que formamos redes educativas múltiplas e que é nelas que nos formamos. Para a pesquisadora (ALVES, 2017), essas redes se apresentam como de 'práticasteorias', pois nelas são possíveis a realização de múltiplos processos educativos pensados por nós incessantemente.

Até o presente, tenho podido trabalhar com as seguintes redes: a das 'práticasteorias' da formação acadêmica; a das 'práticasteorias' pedagógicas cotidianas; a das 'práticasteorias' das políticas de governo; a das 'práticasteorias' coletivas dos movimentos sociais; a das 'práticasteorias' das pesquisas em educação; a das 'práticasteorias' das manifestações artísticas; a das 'práticasteorias' de produção e 'usos' de mídias; e a das 'práticasteorias' de vivências nas cidades, no campo ou à beira das estradas. Essa ideia tem permitido uma compreensão mais complexa da formação e dos currículos uma vez que nos leva a entender o estabelecimento de processos, em uma e nos outros, tanto pelas relações entre os 'praticantespensantes' (OLIVEIRA, 2012) de cada uma delas 
como das relações que se processam de cada uma com as outras. (ALVES, 2017, p. 04).

Para Nilda Alves (2019), as redes educativas das 'práticasteorias' das políticas de governo "incluem uma série de medidas que servem para controlar e organizar, dentro de padrões comuns, os sistemas de ensino que podem ser: federal, estadual ou municipal. Essas políticas aparecem sob forma de leis, decretos [...], resoluções [...] diretrizes, pareceres" (ALVES, 2019, p. 121). Assim sendo, no segundo momento, falaremos das políticas de governo oficiais da educação das relações étnico-raciais.

\section{Movimentos políticos oficiais na padronização de currículos}

A Lei de Diretrizes e Bases da Educação (LDB) (1996) já trazia consigo, ainda na década de noventa, a "necessidade" de uma base nacional comum para os currículos do ensino fundamental e médio ${ }^{6}$. Esse apontamento foi impulsionado progressivamente com a efetivação dos Parâmetros Curriculares Nacionais e uma sucessiva série de políticas curriculares com essa finalidade, como aponta Nilda Alves (2014), culminando na implementação da Base Nacional Comum Curricular, no ano de 2017, para a educação infantil e o ensino fundamental (BRASIL, 2017) e para o ensino médio, em 2018 (BRASIL, 2018).

No presente, discute-se a reforma do ensino médio a partir de uma base comum, como necessidade em um ano pandêmico. O Novo Ensino Médio começará a ser implementado a partir do próximo ano, em 2022. Entre as propagandas veiculadas nas mídias, destacam-se a "nova organização curricular" e "a ampliação da carga horária mínima anual de 800 para 1000 horas", como também já previa a LDB No 9.394 (BRASIL, 1996). No cronograma do Ministério da Educação (MEC) para o ano de 2021, estão as "formações continuadas destinadas aos profissionais de educação" como anuncia o site do governo ${ }^{7}$. Enquanto isso, esses profissionais, em alguns casos, estão sem receber e/ou não tiveram (e ainda não têm) acesso à internet.

Além disso, muitos municípios nem começaram a esboçar o retorno às atividades presenciais devido à precariedade das condições oferecidas. Sem falar do Plano Nacional de Operacionalização da Vacinação contra a COVID-19 (MINISTÉRIO DA SAÚDE, 2021) que caminha de maneira desigual pelos estados brasileiros ${ }^{8}$. Ainda assim, para os órgãos oficiais que coordenam burocraticamente a educação no país, há a necessidade de falarmos de organização curricular para "solucionar" problemas que extrapolam a esfera escolar de estudantes e profissionais de educação.

Todavia, temos visto o engajamento docente em suas múltiplas redes educativas, principalmente com o uso das mídias, reivindicando a parcela que lhes cabe no que diz respeito à formação continuada e apontando o sucateamento do trabalho docente em seus múltiplos aspectos: salarial, estrutural-físico, psíquico, entre outros. Esse engajamento não se dá exclusivamente por via de resistência, mas também de criação cotidiana de políticas. 
Uma delas são as práticas cotidianas para educação das relações étnico-raciais, realizadas pelos 'praticantespensantes' nos/com os cotidianos escolares, pois como aponta Rocha e Lobo (2020, p. 321):

Os processos de escolarização foram formulados com base na invisibilização de grupos de pessoas, sobretudo negras e indígenas. A organização hierárquica das disciplinas nos currículos, que levou a contagem linear da História do mundo e das coisas, centralizada e/ou oriunda da Europa repercute até hoje nos modos pelos quais os currículos oficiais são pensados.

Essas práticas, existentes no presente como forma de rompimento com essa História hegemônica, originaram-se da criação e da luta dos movimentos negros sociais diversos e de politização das questões relativas a cor, raça, etnia, diversidade e racismo que aconteciam nas escolas e que se transformaram em políticas oficiais para educação. A questão racial foi ponto de partida para a organização de outras políticas presentes nas escolas, tais como a Lei $\mathrm{N}^{\mathrm{o}} 13.185 / 15$ de combate à violência no ambiente escolar — bullying — e o Decreto $\mathrm{N}^{\mathrm{o}}$ 8727/2018 que dispõe sobre a identidade de gênero - possibilitando o uso do "nome social". Feitas essas considerações, concentramo-nos agora a refletir a trajetória de luta e políticas cotidianas criadas em prol da educação étnico-racial.

\section{Movimentos cotidianos de criação das políticas curriculares oficiais para a educação das relações étnico-raciais}

Nas últimas décadas no Brasil, aconteceram intensas lutas e resistências, legitimadas com a Constituição Federal de 1988 (BRASIL, 1988), na qual a noção de "diversidade" é apresentada para definir a amplitude das questões étnico-raciais, sendo esta uma conquista de muitos anos de lutas organizadas pelo movimento social negro (GONÇALVES; SILVA, 2000; ROMÃO, 2005; DOMINGUES, 2007). No âmbito educacional, evidenciamos a pertinência da Lei No 10.639/03 (BRASIL, 2003) e Lei No 11.645/08 (BRASIL, 2008) que regulamentam a obrigatoriedade do ensino de História e Cultura Afro-Brasileira, Africana e Indígena em todos os níveis de ensino, conforme afirma a professora pesquisadora Nilma Lino Gomes (2011, p. 120).

É importante reconhecer que a lei n. 10.639/03, o Parecer CNE/CP 03/2004 e a Resolução CNE/CP 01/2004 representam a implementação de ações afirmativas voltadas para a população negra brasileira, as quais são (e devem!) ser desenvolvidas juntamente com as políticas públicas de caráter universal. Trata-se de uma demanda política do Movimento Negro nos dias atuais e de outros movimentos sociais partícipes da luta antirracista na construção da democracia. Uma democracia que assuma o direito à diversidade como parte constitutiva dos direitos sociais e assim equacione de forma mais sistemática a diversidade étnicoracial, a igualdade e a equidade. 
No mesmo sentido, destacamos a institucionalização de políticas antirracistas, com a criação do Estatuto da Igualdade Racial (BRASIL, 2010), a qual reforçou as discussões da temática étnico-racial nas políticas da educação, e salientamos a importância da Política de Cotas Raciais (BRASIL, 2012). Além disso, nos estabelecimentos de ensino público em suas diferentes esferas - municipais, estaduais e federais - já existem secretarias especializadas compostas por docentes que estão comprometidos e mobilizados com tais questões, com destaque para a Gerência de Relações Étnico-Raciais (GERER) da Secretaria Municipal de Educação da Prefeitura do Rio de Janeiro e a Coordenação de Promoção de Igualdade Étnicoracial da Secretaria de Educação e Cultura (COPIED), da Secretaria Municipal de Educação da Prefeitura de Magé, para citar alguns. Mediante o exposto, nosso objetivo é revelar as criações cotidianas que os docentes tecem com a temática da educação das relações étnicoraciais para além dos currículos oficiais.

Assim, no terceiro momento, apresentaremos as políticas cotidianas como práticas coletivas, expondo as experiências das autoras do artigo e de outras professoras com base nas criações cotidianas sobre a educação das relações étnico-raciais das redes educativas das 'práticasteorias' da formação acadêmica-escolar, que "é aquela entendida, oficialmente, como o [ 'espaçotempo'] de formação docente em licenciaturas diversas" (ALVES, 2019, p. 116) e a das 'práticasteorias' pedagógicas cotidianas que

São aquelas que os/as docentes indicam, com frequência, ser os 'espaçostempos' nos quais, efetivamente, se formam. A cotidiana luta neles realizada - que com frequência são ditos como o "chão da escola" - [...] forma o docente para as práticas pedagógicas, curriculares" (ALVES, 2019, p. 118).

\section{Políticas cotidianas como práticas coletivas}

Um momento vivido e observado por muitos nos corredores da Uerj eram as conversas que aconteciam entre um coletivo de mulheres negras do curso de Pedagogia que articulavam suas vivências como estudantes negras em uma universidade pública, atravessando-as com questões como feminismo, trabalho, educação e estética. Esse era um movimento que privilegiava as narrativas e debatia as experiências em comum com suas identidades racial e social, já que muitas mulheres do curso eram oriundas de camadas menos favorecidas socialmente, o que colocava um enorme desafio para conclusão da graduação. Desse modo, historicamente "o movimento negro se organiza - distante dos holofotes das grandes mídias - em práticas de enfrentamento ao racismo e a educação sempre foi um dos pontos principais para tais movimentos, pois sabemos do seu caráter emancipador" como aponta Elaine Sotero, Marco Aurélio Correa e Brenda Coutinho (2020, p. 02).

Um dos temas frequentes dessas conversas era a questão da identidade dos cabelos crespos, uma das ferramentas políticas de afirmação da negritude. Por se tratar de curso de educação, as conversas travadas também eram sobre currículos, pois, algumas daquelas 
mulheres pensavam sobre como estudantes negras lidam com o cabelo crespo dentro das escolas, reconhecendo que meninas negras tendem a apresentar dificuldades com seus cabelos por viverem em uma sociedade que problematiza o cabelo crespo e preza pelo padrão do cabelo liso branco, muitas vezes oriundo do alisamento.

Nessas reuniões, as 'praticantespensantes' tinham a oportunidade de falar sobre suas vivências cotidianas, já que algumas exerciam a profissão docente e outras, provavelmente, seriam professoras. Em qualquer que fosse o grupo, pensavam-se em como poderiam trabalhar com essas questões relacionadas à identidade e aos cabelos crespos, com suas próprias crianças nos cotidianos escolares e compartilhavam entre si possibilidades curriculares de atividades práticas e também de cunho metodológico. Nessa perspectiva, as "subjetividades das professoras e de sua formação estão também em cena, nos 'espaçostempos' da escola e fazendo a importante compreensão de que os 'conhecimentossignificações' são criados em redes [...]” (ROCHA, 2021, p. 68-69).

A partir dessas discussões, elas teciam algumas práticas como oficinas de tranças, turbantes, bonecas com cabelos crespos, não permitindo que a discussão ficasse apenas entre os muros da universidade, entendendo que era de suma importância que elas entrassem nos cotidianos escolares. De acordo com a professora pesquisadora Nilma Lino Gomes (2003, p. 169), "tudo o que produzimos sobre a questão racial na educação e em outras áreas do conhecimento pode ser aproveitado e aplicado na formação de professores [e professoras]". Essas mulheres, como pedagogas em formação, precisavam levar essas 'práticasteorias ' para os cotidianos escolares com o objetivo de traçar novos caminhos para os processos de formação de professoras e professores, procurando ir além dos currículos oficiais e convencionais.

Outra vivência acerca da identidade negra e sua valorização no âmbito da educação das relações étnico-raciais aconteceu em uma escola pública da rede estadual da região norte do Estado do Espírito Santo a partir do projeto Negro Sou. Como resultado de uma atividade para a disciplina de "Educação das relações étnico-raciais" (ERER), ministrada em 2019/2 e 2021/1, pela professora substituta Andreia Teixeira Ramos, do Centro de Educação (CE) do Departamento de teorias de ensino e práticas educacionais (DTEPE) da Universidade Federal do Espírito Santo (Ufes), cinco estudantes do quarto período da licenciatura do curso de Letras Inglês entrevistaram uma professora formada em Letras Português, que atua há 11 anos como docente.

A disciplina de ERER tem como ementa no plano de ensino: abordagem das relações étnico-raciais e políticas afirmativas no contexto brasileiro; relações étnico-raciais, identidades e subjetividades; escola, currículo e a questão étnico-racial na educação básica; raízes históricas e sociológicas da discriminação contra o negro na educação brasileira e a formação de profissionais da educação para o ensino da história e cultura afro-brasileira e africana.

Nesse contexto, os discentes foram orientados na produção de artefatos culturais e pedagógicos como procedimentos avaliativos da disciplina. Entre os trabalhos de conclusão da disciplina de ERER estava a produção de um episódio da Série de Podcast ${ }^{9}$, que teve como interesse expor as discussões apresentadas com o objetivo de intensificar o exercício de 
práticas pedagógicas com comprometimento ético, estético e político na perspectiva da educação antirracista, fortalecendo a formação de professoras e professores nos cotidianos escolares em outras redes educativas. A seguir apresentaremos o episódio "Identidade negra nos cotidianos escolares"10.

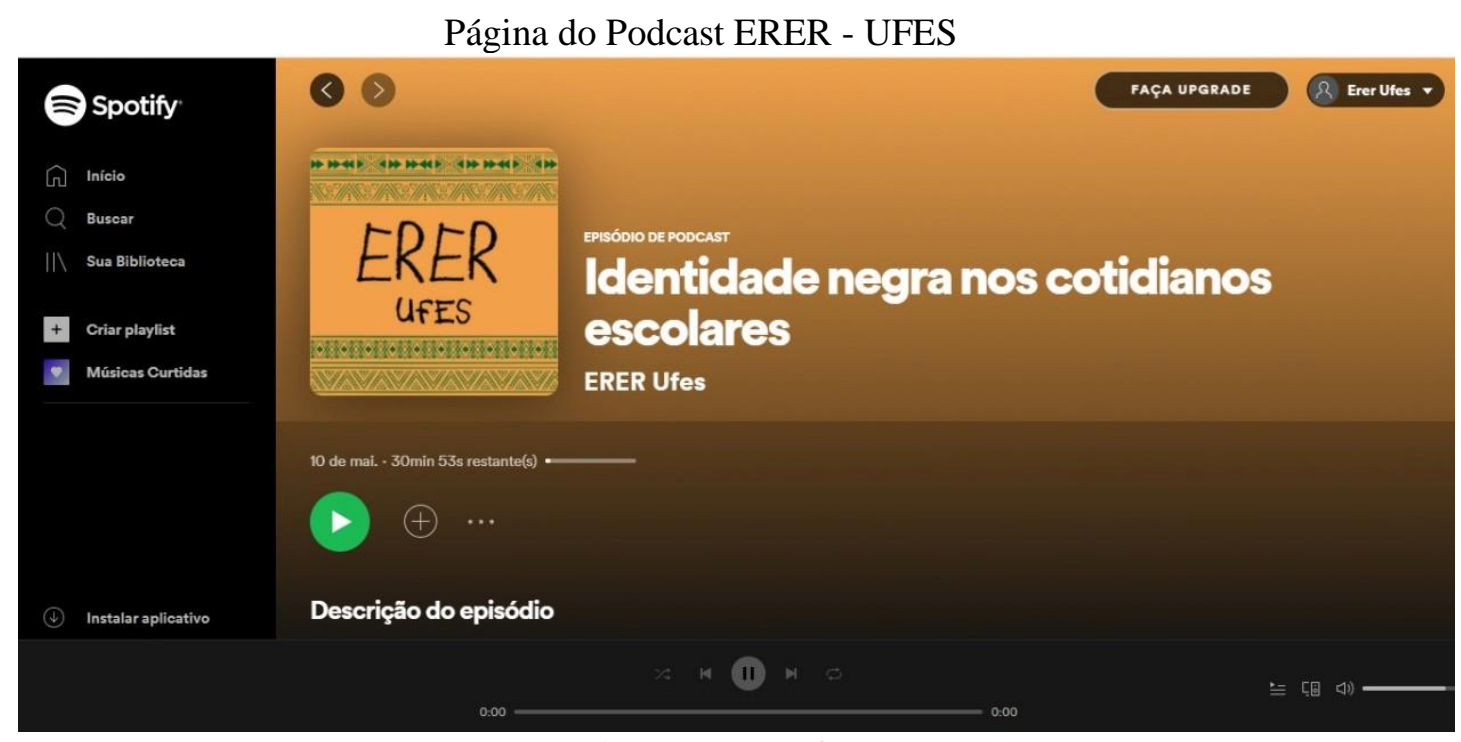

Fonte: Podcast ERER Ufes, 2021.

Os estudantes escolheram trabalhar, nesta edição, o tema "Identidade negra: reconhecimento e valorização", com a intenção de conversar acerca do corpo negro, da consciência e resistências cotidianas experenciadas na sociedade, a partir de situações concretas de atitudes discriminatórias, em que negros e negras se deparam com o padrão de estética eurocêntrico. Para conversar sobre como essa temática tem sido trabalhada nos cotidianos escolares, o grupo de estudantes fez uma entrevista com uma professora de Letras Português que, em parceria com outra professora, leciona a disciplina eletiva "Negro Sou", em uma escola estadual de ensino fundamental e médio em tempo integral, localizada em um município no norte do estado do Espírito Santo.

$\mathrm{Na}$ conversa, a professora regente narra como e quando surgiu a ideia dessa disciplina eletiva, que se tornou o projeto "Negro Sou". A docente destacou como foi a recepção na comunidade escolar em geral e o impacto do projeto na questão da autoestima e da autodeclaração da identidade negra na sociedade. Expôs a relação e o envolvimento dos jovens com a disciplina e finalizou salientando como tem realizado suas práticas pedagógicas com a chegada da pandemia da Covid-19. Ela ainda narra que muitos dos desafios e problemáticas que já existiam foram potencializados e novos surgiram, posto que na atualidade é necessário criar procedimentos metodológicos para manter os estudantes conectados às aulas. O desenvolvimento do projeto "Negro Sou" foi pertinente no sentido de incentivar práticas de autoaceitação e empoderamento da identidade negra por parte dos estudantes e da sociedade em geral. De acordo com essa professora que é docente da 
disciplina de Língua Portuguesa em uma escola pública em tempo integral o projeto possibilitou

trabalhar com mais afinco a pauta da identidade negra. O projeto "Negro Sou" [...] surgiu como um projeto de uma professora de Língua Portuguesa que trabalhava além da sua disciplina, [...] a questão de identidade nas escolas por onde ela passava e quando em 2019 eu fui para [essa] escola, ao me deparar com uma grade curricular que me permitia trabalhar a disciplina eletiva, conheci [essa] professora que é natural de Minas e tinha interesse de trabalhar essa pauta mais voltada para a questão capilar na verdade. Ela queria criar uma disciplina que tratasse de cabelos crespos e cacheados e quando nós nos encontramos, nós decidimos transformar o projeto "Negro Sou" em uma disciplina eletiva. [...] Além de trabalhar essa questão estética, nós tivemos o foco de trabalhar realmente a autoaceitação e empoderamento de jovens negros nas escolas.

A narrativa da professora reforça o que Nilda Alves (2019) indicava ser a rede educativa das 'práticasteorias' pedagógicas cotidianas. A docente narra um processo formativo em duas vias, ou ainda de acordo com Alves (2019), uma formação 'docentediscente', ou seja, a professora formar-se metodológica e epistemologicamente na criação de processos formativos que levam os jovens negros à autoaceitação e ao empoderamento. Todavia, por ser espaço escolar, ela precisou estabelecer uma disciplina para que pudesse trabalhar a temática. Um jogo político de escapar ao convencionalismo do currículo oficial e criar táticas para uma prática pedagógica outra dentro do mesmo currículo instituído, operando, dessa forma, os currículos 'pensadospraticados' nos cotidianos escolares (OLIVEIRA, 2012).

Nesse contexto, de acordo com Inês Barbosa de Oliveira (2012, p. 45), além da centralização no conhecimento formal e na sua difusão, "habitadas pelas emoções - prazeres e rejeições - dos sujeitos da escola, essas experiências de ['praticantespensantes'] de currículos que não são apenas aquilo que está escrito e registrado nas propostas curriculares" salientam valiosas criações pedagógicas que são criadas por esses 'praticantespensantes', "com base também em critérios de prazer. Por meio dessas criações, [professoras e professores e estudantes] revelam-se, fazem emergir sua condição de criadores, [autoras e] autores dos currículos escolares" (2012, p. 45). Assim, mesmo com todos os dispositivos de regulação, a vida escapa nos cotidianos escolares, sendo possível criações de múltiplos conhecimentos em diferentes 'espaçostempos' das redes educativas, fortalecendo 'os fundamentais currículos que são criados cotidianamente" como destaca Inês Barbosa de Oliveira (2012, p. 52).

O primeiro objetivo era identificar porque o maior percentual de estudantes da rede estadual não se declaravam negros no ato de matrícula. Nós fizemos esse levantamento e conseguimos observar que os estudantes em sua maioria, quase todos, não se declaravam negros, essa é uma realidade do nosso estado, das nossas escolas em geral, porque ninguém quer ser negro. [...] A primeira situação que nós detectamos foi essa e depois o que nós poderíamos fazer para promover a 
autoaceitação desses estudantes na escola, fazer com que eles tivessem esse sentimento de pertencimento, que conhecessem a história deles, conhecessem o direito deles [e] conseguissem se sentir negros dentro desse ambiente que eles eram maioria, não eram minoria, porém, os dados diziam o contrário. [...] Fizemos um burburinho muito grande na escola, foi uma movimentação bem intensa já na apresentação da disciplina. A movimentação foi grande, foi positiva, mas foi forte em vários aspectos, nós tivemos reações positivas e nem digo negativas, reações esperadas, não só de alguns estudantes, como de alguns profissionais, porque é uma temática que causa desconforto e nosso objetivo é esse, era realmente causar desconforto. O "Negro Sou" trata da questão do negro em todas as esferas, a gente tenta levar para os estudantes conhecimento histórico, [...] ofertar oficinas de embelezamento, rodas de conversa sobre autoaceitação e todas essas movimentações sempre que possível nós fazemos assim, levando, potencializando aquilo que nós já temos, nem tudo que é trabalhado na eletiva é simplesmente direcionado e feito por Jaqueline e eu, nós por exemplo, se eu estou trabalhando sobre questões relacionadas sobre História, eu levo um profissional negro que represente essa pauta para trabalhar. Se eu estou falando sobre a questão de direitos, nós tivemos a oportunidade de levar também advogados, pessoas negras que tem, porque estudantes negros precisam ter essa visibilidade, essa noção de representatividade, certo? Sempre que nós temos oportunidade e somente em 2019 eu descobri que nós temos uma comunidade de remanescentes quilombolas reconhecidos aqui, eu só tinha conhecimento de comunidades quilombolas em São Mateus, que é minha cidade natal, através dos estudos e da eletiva, eu consegui proporcionar o quê? Conhecimento desses estudantes fazendo essa ligação, tanto trazer pessoas da comunidade até a escola, quanto conseguimos levar os estudantes para conhecer a comunidade quilombola, tudo isso gerou não só na comunidade escolar em geral, mas na cidade, uma movimentação bem intensa, o projeto ficou conhecido, nós tivemos participação em alguns programas televisivos também, não só no mês da Consciência Negra, que infelizmente é uma realidade, a pauta mais elencadas nesse período, mas nós tivemos participação durante o ano, foi um ano bem intenso e a gente consegue até hoje ainda colher frutos de toda essa movimentação, nós trabalhamos de uma forma, começamos de uma forma bem pequena com esse objetivo de trabalhar mais a autoaceitação daqueles indivíduos ali, daqueles estudantes, mas ele tomou, a proposta do projeto e da disciplina tomou uma dimensão muito maior. Nós conseguimos movimentar a valorização e empoderamento dentro de alguns profissionais, nós fizemos desfiles da realeza africana e convidamos não só estudantes, mas também profissionais da escola para participar, para representar a realeza africana. Os meninos começaram a achar interessante porque eles viam um guarda lá desfilando na escola, eles viam as serventes lá participando da eletiva também, nós tivemos estagiários, guardas, serventes, vários profissionais, intérpretes, monitores, todo mundo que se reconhecia como negro, porque também nós tivemos alguns profissionais negros que não participaram, porque essa questão da negritude a pessoa tem que se reconhecer. Fizemos esse movimento e eu acredito que o impacto social foi assim, bem grande, eu diria que gigantesco. 
O trabalho da professora ainda é atravessado por outras redes educativas, as das 'práticasteorias' das pesquisas em educação, as das 'práticasteorias' dos movimentos sociais e das 'práticasteorias' das políticas de governo. O trabalho de pesquisa, no qual as professoras e os professores são inseridos diariamente para tentar entender seus cotidianos de quererfazer, compreende a dimensão do fazer docente que escapa aos dispositivos de regulação, porque ele atravessa também as políticas de governo, absorvendo-as e dando outras formas nas escolas. Os movimentos sociais também são de extrema importância na criação de currículos nas escolas, pois em articulação com as "pessoas comuns" eles pressionam os governos a atender demandas populares.

Nessa direção, a professora pesquisadora e intelectual negra Nilma Lino Gomes (2012, p. 735) destaca que a educação durante todo percurso histórico tem recebido um cuidado particular "das entidades negras. Ela é compreendida pelo movimento negro como um direito paulatinamente conquistado por aqueles que lutam pela democracia, como uma possibilidade a mais de ascensão social". Desse modo, o movimento social negro acentua e exercita a luta e a necessidade de "produção de conhecimentos que valorizem o diálogo entre os diferentes sujeitos sociais e suas culturas e como espaço de formação de cidadãos que se posicionem contra toda e qualquer forma de discriminação" (GOMES, 2012, 735). Assim sendo, ao trabalhar a autoaceitação e o empoderamento com os estudantes, essas professoras criam alternativas pedagógicas com prática antirracista que fortalecem os processos de identificação dos discentes negros, descontruindo as narrativas de representações discriminatórias que habitam em nossa sociedade.

Nós fizemos um trabalho interessante que foi uma exposição fotográfica sobre mulheres negras que marcaram a História, nesse trabalho nós convidamos todos os profissionais negros, as mulheres negras da escola a participar, professoras, estagiárias, serventes, estudantes também que faziam parte da eletiva e homenageamos diversas mulheres, foi um trabalho gigantesco e em meio aos intervalos, horinhas de planejamento, em um momentinho de intervalo, um colega ajudando... enfim, fizemos releitura homenageando essas mulheres negras que marcaram a História. A exposição com a releitura fotográfica ficou tão linda, com uma qualidade tão interessante assim, tão gigantesca e a participação também de algumas pessoas da comunidade serve também para valorizar o trabalho e nós fomos convidados a fazer a exposição em outros lugares, levamos também no IFES, Campus Linhares, fizemos a exposição lá, foi um trabalho fantástico que eu me orgulho muito de ter participado, o que nós percebemos é que o carinho e que digamos assim, a proximidade que esse trabalho trouxe de alguns profissionais com os estudantes, porque em uma escola de tempo integral a gente trabalha a Pedagogia da Presença, agora a gente não pode ter muito contato[por causa da pandemia], mas é uma escola que tem abraço, quem não estudou em uma escola como essa, mas eu acredito que já deva ter passado sabe... é abraço, é cumprimentar, é saber realmente o nome das pessoas, os estudantes sabem quem é o vigilante, sabem o nome dele, entendeu? Esse trabalho trouxe uma proximidade ainda maior. Tinha uma estagiária lá que às vezes o pessoal não sabia 
nem que ela era estagiária... aquela tia da cozinha, que às vezes você chama de tia da cozinha, agora tem o nome da tia da cozinha ali, tem a foto dela, o registro do trabalho dela e assim, a gente recebia muitas mensagens desses profissionais dizendo como foi importante, como eles se sentiram digamos né, aquela sensação de pertencer mesmo, não só na escola, mas se reconhecer como negro em uma ação que trazia orgulho e até hoje a gente colhe frutos dessa ação.

As redes educativas que nos formam têm muitos fios e, por isso, muitas implicações. $\mathrm{O}$ que nos faz compreender as redes educativas de 'práticasteorias' do uso da mídia e sua relevância, como aponta Nilda Alves (2019). Na tentativa de escapar às regulações, o uso das mídias e de recursos audiovisuais tem sido essencial na formação de opinião em debates sociais importantes e como recurso tecnológico de longo alcance. Ao acessarmos a internet e buscarmos informações sobre inúmeros assuntos, é extremamente comum nos depararmos com influencers, youtubers e blogueiros que falam em suas plataformas sobre questões que são essenciais nos cotidianos.

Apesar da gama de informações que podemos acessar com essas mídias, existe ainda uma resistência de algumas pessoas em considerar esses canais como meios de informações que possam elaborar e contribuir com os currículos 'pensadospraticados' nos cotidianos escolares, os quais são criações cotidianas dos 'praticantespensantes' nesses 'espaçostempos' e que acontecem, "por meio de processos circulares em que se enredam conhecimentos, valores, crenças e convicções que habitam diferentes instâncias sociais, diferentes sujeitos individuais e sociais em interação" (OLIVEIRA, 2012, p. 90).

Nesse cenário, por meio do artigo "Artefatos tecnoculturais nos processos pedagógicos: usos e implicações para os currículos", as professoras Conceição Soares e Edmeia Santos (2012) nos ajudam a pensar a formação de professoras e de professores na cibercultura, isto é, para além dos '[...] ['espaçostempos'] da escola e da universidade. Estes historicamente, principalmente na modernidade, foram os legítimos espaços de formação e da instituição dos Currículos" (SOARES; SANTOS, 2012, p. 329). Nesse sentido, na contemporaneidade, precisamos lidar e interagir com o mundo tecnológico, rompendo com os desafios formativos dos nossos 'espaçostempos' atuais e facilitando a circulação, a vivência e o acesso aos artefatos tecnológicos (SOARES; SANTOS, 2012), relacionados às redes sociais do presente momento, incluindo-os nos processos pedagógicos cotidianos e curriculares que realizamos nas redes educativas.

Essa conversa nos fez recordar o álbum "Quanto", de 1997, de Gilberto Gil, que 21 anos depois atualizou a canção "Pela internet" para "Pela internet 2", lançada pelo álbum OK OK OK em 2018. Na canção Gilberto Gil diz:

Criei meu website

Lancei minha homepage

Com 5 gigabytes

Já dava pra fazer

Um barco que veleje 
Meu novo website

Minha nova fanpage

Agora é terabyte

Que não acaba mais

Por mais que se deseje

Que o desejo agora é garimpar

Nas terras das serras peladas virtuais

As criptomoedas, bitcoins e tais

Não faz economias, novos capitais

Se é música o desejo a se considerar

É só clicar que a loja digital já tem

Anitta, arnaldo antunes, e não sei mais quem

Meu bem, o itunes tem

De a a z quem você possa imaginar

Estou preso na rede

Que nem peixe pescado

É zapzap, é like

É instagram, é tudo muito bem bolado

O pensamento é nuvem

$O$ movimento é drone

O monge no convento

Aguarda o advento de Deus pelo iphone

Cada dia nova invenção

É tanto aplicativo que eu não sei mais não

What's app, what's down, what's new

Mil pratos sugestivos num novo menu

É facebook, é facetime, é google maps

Um zigue-zague diferente, um beco, um cep

Que não consta na lista do velho correio

De qualquer lugar

Waze é um nome feio, mas é o melhor meio

De você chegar

Com essa atualização da música "Pela internet 2", Gilberto Gil convida a mantermo-nos conectados aos dias atuais. Nesse sentido, nós — professoras e professores — como seres históricos temos a capacidade de intervir e conhecer o mundo. Para tanto, é necessário aprender para ensinar, sendo que ensinar exige pesquisa, como nos afirmou Paulo Freire (2009, p. 29): "não há ensino sem pesquisa e pesquisa sem ensino [...]. Pesquiso para constatar, constatando, intervenho, intervindo educo e me educo. Pesquiso para conhecer o que ainda não conheço e comunicar ou anunciar a novidade". Nesse caminhar, com a pandemia da Covid-19, nós docentes fomos convocados e provocados a exercitar atitude criadora diante de tudo que estávamos vivendo, de novo e inesperado, pesquisando para aprender a lidar com as situações concretas que desafiaram os processos de “['aprendizagemensino'] que ocorrem em meio à tessitura de práticas cotidianas em redes, 
muitas vezes contraditórias, [...] de possibilidades e limites, de diálogos e embates" (ALVES; OLIVEIRA, 2012, p. 71), e também que podem ser produzidas por meio de enredamentos das 'práticasteoriasteorias' em currículos nos cotidianos escolares e em outras redes educativas. Neste contexto, com a chegada inesperada da pandemia as práticas pedagógicas que eram realizadas com os estudantes foram recriadas nos múltiplos 'espaçostempos' com os usos das novas tecnologias.

A pandemia veio e afetou todos de formas diversas, no caso da eletiva, o que nós fizemos... além dos estudantes estarem inseridos num grupo de WhatsApp das turmas e também nas salas digital, nós temos um WhatsApp próprio para a eletiva, essas duas turmas estão em um grupo do WhatsApp, o grupo se chama "Negro Sou digital". É a nova modalidade da disciplina eletiva, nós também temos [também] o Instagram ${ }^{11}$. A eletiva no formato digital continua trabalhando as mesmas pautas e o que nós temos tentado realmente é manter o contato "indivíduo-indivíduo", chamar o menino no privado, conversar, tentar descobrir o que está acontecendo, quais são as necessidades dele, alguns nos chamam, compartilham as atividades que eles têm conseguido fazer, aquilo que eles têm tido mais dificuldade, o que nos deixa mais preocupados realmente com esse distanciamento são as questões mais relacionadas à violência mesmo por esses estudantes, que já estão dentro de um grupo de risco, estão distantes e não conseguem compartilhar, porque alguns deles não usam o seu aparelho celular, eles usam o de responsáveis e isso a gente consegue contactar, falar pessoalmente, grande parte deles... uns chamam, compartilham conosco situação de racismo que eles vivenciaram, coisas que eles aprenderam e agora eles conseguem observar o racismo por trás daquilo que eles viram na rede social e aí nos marcam, compartilham, é algo bem interessante. Essa semana eu tive contato com uma mulher, uma senhora e eu fui descobrir que ela era mãe de um estudante que fez parte da eletiva e eu achei muito interessante quando ela disse o seguinte: "Eu aprendi tanta coisa quando o meu filho estava na eletiva porque ele usava o meu celular e eu lembro que uma vez você fez uma oficina, vocês fizeram uma oficina de umas bonequinhas...". Na verdade foi uma oficina de bonecas Abayomi ${ }^{12}$ e quem deu a oficina foi a minha irmã, veio de São Mateus e deu a oficina. Ela viu essa movimentação toda no celular dele e por questões religiosas e por falta de conhecimento, pensava que aquelas bonequinhas, eram bonecas que são utilizadas em rituais vudus e quando viu no celular dele aquelas imagens ela ficou interessada e disse que começou a compartilhar, olhar e ver do que se tratava... perguntou para ele e ele foi contar a história para ela, a história das bonecas Abayomi, qual era o contexto dessa história e ela disse que ficou muito emocionada, chorou, se sentiu envergonhada. Eu fiquei tão feliz quando ela compartilhou isto. $\mathrm{O}$ estudante não está mais na escola [...] conseguiu seguir o projeto de vida dele e eu fiquei muito feliz e é isso, a gente não consegue impactar $100 \%$ do grupo da mesma forma que no presencial, mas a gente segue tentando e não desistindo. 
Muitos temas são discutidos por meio das mídias e de outros recursos tecnológicos, tais como: feminismo, movimento social negro, racismo, cotas, gêneros e sexualidades, combate à atual política genocida entre muitos outros. Todas essas questões são pertinentes para a criação de currículos em nossos cotidianos, pois debatem, evidenciam e partilham conhecimento sobre temas e questões que estão presentes nos cotidianos escolares, queiram os currículos oficiais ou não. Esses mecanismos têm sua relevância ampliada especialmente pelo momento pandêmico, pois permitiram que essas redes educativas diversas se articulassem e não parassem de criar currículos cotidianamente, ainda que fora do "chão da escola".

Assim, para Paulo Freire (2009, p. 36), "faz parte igualmente do pensar certo a rejeição mais decidida a qualquer forma de discriminação. A prática preconceituosa de raça, de classe, de gênero ofende a substantividade do ser humano e nega radicalmente a democracia". Nessa direção, Nilma Lino Gomes comenta que

O ser humano se constitui por meio de um processo complexo: somos ao mesmo tempo semelhantes (enquanto gênero humano) e muito diferentes (enquanto forma de realização do humano ao longo da história e da cultura). Podemos dizer que o que nos torna mais semelhantes enquanto gênero humano é o fato de todos apresentarmos diferenças: de gênero, raça/etnia, idades, culturas, experiências, entre outros. E mais: somos desafiados pela própria experiência humana a aprender a conviver com as diferenças. O nosso grande desafio está em desenvolver uma postura ética de não hierarquizar as diferenças e entender que nenhum grupo humano e social é melhor ou pior do que outro. Na realidade, somos diferentes (GOMES, 2007, p. 22).

Nesse caminhar, afirmando as nossas diferenças enquanto seres humanos e pensando nas múltiplas redes educativas, a professora pesquisadora Nilma Lino Gomes (2007, p. 41) ressalta que "a diversidade é muito mais do que o conjunto das diferenças [...] [é] construção histórica, social e cultural das diferenças a qual está ligada às relações de poder, aos processos de colonização e dominação". Assim, é necessário ficarmos atentos às situações concretas de desigualdades sociais e raciais presentes em nossa sociedade, as quais adentram os cotidianos escolares e tentam "apagar" as diferenças dos sujeitos 'pensantespraticantes'. Logo, "assumir a diversidade é posicionar-se contra as diversas formas de dominação, exclusão e discriminação. É entender a educação como um direito social e o respeito à diversidade no interior de um campo político" (GOMES, 2007, p. 41).

Nesse sentido, com essas atividades propostas pela professora entrevistada no Podcast, é possível notar como é pertinente que essas discussões sejam corporificadas nos currículos 'pensadospraticados' na atualidade, promovendo debates com os conhecimentos escolares, com as relações sociais, com os valores e com os processos de identificação dos estudantes, de modo a criar brechas para escapar dos dispositivos de regulação das políticas oficiais de currículo como movimentos de resistência da educação das relações étnico-raciais. 


\section{Considerações finais}

Concluímos reforçando a necessidade das práticas sociais como fomentadoras e catalisadoras de políticas cotidianas, o que inclui as políticas curriculares e seus movimentos permanentes nos/dos/com os cotidianos escolares, em concordância com os estudiosos do campo apresentados e outros. $\mathrm{O}$ uso das mídias e a noção de redes educativas, que temos trabalhado ao longo do texto, faz-nos perceber e evidenciar que as práticas sociais tecem 'conhecimentossignificações' que vão sendo transformados em políticas cotidianas à medida que ganham movimentos.

Nilda Alves (2010, p. 1209-1210) esclarece que "os movimentos parecem ter desaparecido, porque estão submersos em dificuldades e ações minúsculas que não se deixam ver ou não são vistas pelos modos de ver hegemônicos na sociedade". A potência dos estudos com os cotidianos está justamente em fazer enxergar esses pequenos movimentos que, por meio da prática, tornam-se políticas, inclusive curriculares, como a prática da professora narrada acima. No mesmo sentido, afirma Rocha (2021):

As tentativas de aprisionar, fixar, enrijecer, compartimentar e burocratizar o conhecimento têm sido frequentemente frustradas pelos 'praticantespensantes' 'docentesdiscentes' das escolas, justamente pelo agenciamento permanentemente coletivo na criação dos currículos com os cotidianos, pelo "uso" de artefatos diversos nos cotidianos escolares e das novas maneiras de 'aprenderensinar' introduzidas por professores de forma rizomática, dando seguimento aos “currículos praticados" (ROCHA, 2021, p. 72).

Todavia, as instituições oficiais tentam controlar essas ações, ora incluem - como no caso das leis 10.639 e 11.645 -, ora alteram - como a tentativa de apagamento da mesma educação antirracista na BNCC - sempre jogando com as práticas sociais e seus movimentos ou com o que conseguem capturar deles. No entanto, professoras e professores, em diferentes esferas de atuação, têm criado práticas para lutar contra qualquer política que tente limitar suas possibilidades de fazer uma educação política, problematizadora e como prática de liberdade (FREIRE, 2009, 2014a), pois se os órgãos de controle fazem uso do seu "poder panóptico" (CERTEAU, 2014, p. 100), docentes e discentes, em suas posições quase "microbianas", estão infiltrados (CERTEAU, 2014, p. 41) nos cotidianos das escolas, criando alianças microscópicas, multiformes e inumeráveis (CERTEAU, 2014, p. 52). Nesse sentido seguimos nossos caminhos no esperançar da pedagogia freireana,

no exercício democrático, na lida-luta cotidiana pelo direito à vida digna, contra todos os tipos de desigualdades sociais e raciais, em favor da equidade e da liberdade de ser no mundo e com o mundo, resistindo a todos os modos de autoritarismo do patriarcado capitalista de supremacia branca que tentam nos impedir de sermos mais. Seguimos no esperançar, reconhecendo a necessidade do diálogo amoroso e da alegria como fundamento da educação como prática de liberdade com o desejo de reinventar práticas pedagógicas dialógicas como 
possibilidade de criação de currículos nos cotidianos escolares (RAMOS; GONZALEZ, 2020, p. 590).

Assim, continuamos nossas trajetórias acreditando na potência de outros modos de criações cotidianas para além dos dispositivos de regulação da docência, presentes nas políticas de currículo na atualidade e manifestos em dispositivos, como os da educação para as relações étnico-raciais, que reconhece os cotidianos escolares e outras redes educativas como espaços de autonomia e de práticas de liberdade em diálogo com Paulo Freire, pois, compreendemos que "mudar é difícil mas é possível" (2014b, p. 93).

Nesse sentido, Nilda Alves (2017, p. 16) nos diz ainda que "ao resistirmos às mudanças que as forças retrógadas desejam implantar estamos combatendo no campo delas. Criar outros caminhos permite lutar dentro de agendas que são nossas", e compreendemos que isso nos empurra esperançosas à ações e lutas cotidianas, negociando as tensões e os conflitos e exercitando o diálogo amoroso com alegria e boniteza freireana com a intenção de fortalecer práticas pedagógicas antirracistas e antipatriarcal ${ }^{13}$ (RAMOS, 2020; 2021a; 2021b) na formação de professoras e professores para reamanhecer esperanças em nós, ecoando movimentos insubmissos poéticos de vozes-resistências de Conceição Evaristo $(2016 ; 2017)$ na criação cotidiana de outros mundos possíveis.

\section{Notas:}

1. Essa forma de grafar tem sido usada para dar conta de superar as dicotomias e separações entre elementos de expressões que nos parecem ficar melhor quando juntos e não dicotomizados. Essa herança da modernidade tem-se mostrado como limite às pesquisas com os cotidianos que desenvolvemos" (ALVES; OLIVEIRA, 2012, p. 61). "Esses termos e tantos outros que ainda aparecerão neste texto, estão assim grafados porque, há muito, o grupo de pesquisa no qual percebeu que as dicotomias necessárias à criação das ciências na Modernidade têm significado limites ao que precisamos criar na corrente de pesquisa a que pertencemos, as chamadas pesquisas nos/dos/com os cotidianos. Com isto, passamos a grafar deste modo os termos: juntos, em itálico e entre aspas simples. Estas últimas foram acrescentadas com vistas a deixar [evidente] aos revisores/as de textos que é assim que esses termos precisam aparecer" (LOBO, 2021, p. 13).

2. Conforme Nilda Alves e Inês Barbosa de Oliveira (2012, p. 61-62), "O aprender aparece antes do ensinar por convicção epistemológica de que a aprendizagem precede o ensino tanto cronológica - para ensinar é preciso ter aprendido - quanto epistemologicamente, considerando-se nossa opção pela subversão das crenças hegemônicas a respeito desses processos".

3. As autoras defendem a ideia de bricolagens a partir de Certeau (2014) para tratar as criações cotidianas que alteram regras, práticas, formas e conteúdos na criação de processos curriculares e culturais, que escapam da regulação e dos modelos hegemônicos fixados.

4. Fizemos aqui uma atualização da escrita de 'conhecimentos e significações', como orientado pela autora, que fez a atualização da palavra em seus últimos textos e explicou tal necessidade para as pesquisas com os 
cotidianos, em nota, no texto "Os movimentos necessários às pesquisas com os cotidianos - após muitas 'conversas' acerca deles" (ANDRADE; CALDAS; ALVES, 2019, p. 22).

5. A grafia aglutinada das palavras se dá pelo mesmo motivo da nota anterior, em concordância com Nilda Alves (2019), que diz que algumas palavras escritas separadamente, apresentavam certa dicotomia e limitavam os movimentos das pesquisas com os cotidianos (ANDRADE; CALDAS; ALVES, 2019, p. 19).

6. No ano de 2013, o artigo 26 foi alterado pela Lei $n^{\circ} 12.796$, que incluiu também o currículo da educação infantil (BRASIL, 1996).

7. Disponível em: https://www.gov.br/mec/pt-br/assuntos/noticias/mec-formara-professores-paraimplementacao-do-novo-ensino-medio-no-brasil. Acesso em: 7 dez. 2021.

8. O "vacinômetro" demonstra progressão na vacinação após a escritura do artigo, mostrando o avanço na imunização no Brasil, mas as disparidades regionais ainda são grandes. Disponível em: https://conselho.saude.gov.br/vacinometro. Acesso em: 7 dez. 2021.

9. Podcast "é um programa de rádio que pode ser ouvido pela internet a qualquer hora, por meio do celular ou do computador. Com temas e duração variadas, o ouvinte pode acessar conteúdos em áudio para se informar, para estudar ou para passar o tempo". Disponível em: https://www.brasildefatomg.com.br/2021/02/10/oque-e-um-podcast-para-que-serve-conheca-algumas-sugestoes-de-programas. Acesso em: 6 ago. 2021.

10. Episódio de Podcast ERER Ufes. Disponível em: https://open.spotify.com/episode/6KUJr6rF5RNMsqDwVNBwju. Acesso em: 6 ago. 2021. Recomendamos consultar "O Podcast: Cotidianos e Currículos do grupo de pesquisas: Currículos cotidianos: redes educativas, imagens e sons, coordenado por Nilda Alves e ligado ao programa em pós-graduação em educação ProPed/ UERJ - Maracanã e ao programa de pós graduação em educação: Processos Formativos e Desigualdades sociais, UERJ/FFP São Gonçalo, [que] surgiu de uma ideia de Fernanda Cavalcanti de Mello, doutoranda do grupo de pesquisas e teve sua primeira edição em agosto de 2020. Pode ser acessado através do Spotify, Anchor, Deezer, RadioPublic e Breaker (LOBO, 2021, p. 13-14). Disponível em: https://open.spotify.com/show/7dSrD9L0b9vVf0LMrRdI7h. Acesso em: 10 set. 2021.

11. Endereço da página do Instagram do Projeto Negro Sou. Disponível em: https://www.instagram.com/negro.sou/?hl=pt-br. Acesso em: 20 ago. 2021.

12. História da boneca Abayomi. Disponível em: https://lunetas.com.br/bonecasabayomi/?fbclid=IwAR3vUhee8BVw0qa9yrUStJSH4C11O-v5sdbShDtFx05Sfuq0MJWS2quo0Yc. Acesso em: 07 dez. 2021.

13. "Patriarcado capitalista de supremacia branca", [de acordo com] a escritora, professora e intelectual insurgente e inquieta, bell hooks (2019, p. 20), uma mulher negra estadunidense, referindo-se a uma organização social definida pela dominação masculina, onde existe o predomínio econômico e político representado pelo poder do homem ocidental europeu branco desde a colonização (BENTO, 2014, p. 53), sistema que inferioriza e oprime tudo que está fora deste padrão de referência” (RAMOS, 2021a, p. 43).

\section{Referências}

ALVES, Nilda. A compreensão de políticas nas pesquisas com os cotidianos: para além dos processos de regulação. Educ. Soc., Campinas, v. 31, n. 113, p. 1195-1212, out./dez. 2010.

ALVES, Nilda. Sobre a possibilidade e a necessidade curricular de uma base nacional comum. Revista eCurriculum, São Paulo, v. 12, n. 3, p. 1464-1479, out./dez. 2014.

ALVES, Nilda. Formação de docentes e currículos para além da resistência. Revista Brasileira de Educação, 
[s. 1.], v. 22, n. 71, 2017, e227147.

ALVES, Nilda. Sobre redes educativas que formamos e que nos formam. In: ALVES, Nilda. Práticas pedagógicas em imagens e narrativas: memórias de processos didáticos e curriculares para pensar as escolas hoje. São Paulo: Cortez, 2019. p. 115-133.

ALVES, Nilda; OLIVEIRA, Inês Barbosa de. Ensinar e aprender/ "aprenderensinar": o lugar da teoria e da prática em currículo. In: ALVES, Nilda; LIBANEO, José Carlos (org.). Temas de pedagogia: diálogos entre didática e currículo. São Paulo: Cortez, 2012.

ANDRADE, Nivea; CALDAS, Alessandra Nunes; ALVES, Nilda. Os movimentos necessários às pesquisas com os cotidianos - após muitas 'conversas' acerca deles. In: OLIVEIRA, Inês Barbosa de; PEIXOTO, Leonardo Ferreira; SUSSEKIND, Maria Luiza (org.). Estudos do cotidiano, currículo e formação docentes - questões metodológicas, políticas e epistemológicas. Curitiba: CRV, 2019, p. 19-46.

BENTO, Maria Aparecida Silva. Branqueamento e branquitude no Brasil. CARONE, Iray; BENTO, Maria Aparecida Silva (Orgs.). Psicologia social do racismo: estudos sobre branquitude e branqueamento no Brasil. Petrópolis: Vozes, 2002, p. 25-58.

BRASIL. [Constituição (1988)]. Constituição da República Federativa do Brasil. Brasília, DF: Presidência da República, 1988. Disponível em: http://www.planalto.gov.br/ccivil_03/constituicao/constituicao.htm. Acesso em: 10 set. 2021.

BRASIL. Lei $\mathbf{n}^{\mathbf{0}}$ 9.394, 20 de dezembro de 1996. Estabelece as diretrizes e bases da educação nacional. Brasília, DF: Presidência da República, 1996. Disponível em: http://www.planalto.gov.br/ccivil_03/leis/19394.htm. Acesso em: 10 set. 2021.

BRASIL. Lei no 10.639, de 9 de janeiro de 2003. Altera a Lei no 9.394, de 20 de dezembro de 1996, que estabelece as diretrizes e bases da educação nacional, para incluir no currículo oficial da Rede de Ensino a obrigatoriedade da temática "História e Cultura Afro-Brasileira", e dá outras providências. Brasília, DF: Presidência da República, 2003. $\quad$ Disponível em: http://www.planalto.gov.br/ccivil_03/leis/2003/110.639.htm. Acesso em: 10 set. 2021.

BRASIL. Lei $\mathbf{n}^{\mathbf{0}}$ 12.288, de 20 de julho de 2010. Institui o Estatuto da Igualdade Racial [...]. Brasília, DF: Presidência da República, 2010. Disponível em: http://www.planalto.gov.br/ccivil_03/_ato20072010/2010/lei/112288.htm. Acesso em: 19 jul. 2021.

BRASIL. Lei $\mathbf{n}^{\mathbf{0}}$ 11.645, de 10 de março de 2008. [...] estabelece as diretrizes e bases da educação nacional, para incluir no currículo oficial da rede de ensino a obrigatoriedade da temática "História e Cultura AfroBrasileira e Indígena". Brasília, DF: Presidência da República, 2008. Disponível em: http://www.planalto.gov.br/ccivil_03/_ato2007-2010/2008/lei/111645.htm Acesso em: 19 jul. 2021.

BRASIL. Lei $\mathbf{n}^{\circ}$ 12.711, de 29 de agosto de 2012. Dispõe sobre o ingresso nas universidades federais e nas instituições federais de ensino técnico de nível médio e dá outras providências. Brasília, DF: Presidência da República, 2012. Disponível em: http://www.planalto.gov.br/ccivil_03/_ato20112014/2012/lei/112711.htm. Acesso em: 19 jul. 2021.

BRASIL. Lei $\mathbf{n}^{\mathbf{0}}$ 13.185, de 06 de novembro de 2015. Institui o Programa de Combate à Intimidação Sistemática (Bullying). Brasília, DF: Presidência da República, 2015. Disponível em: http://www.planalto.gov.br/ccivil_03/_ato2015-2018/2015/lei/113185.htm. Acesso em: 19 jul. 2021.

BRASIL. Ministério da Educação. Secretaria Especial de Políticas de Promoção da Igualdade Racial. Diretrizes Curriculares Nacionais para a Educação das Relações Étnico-Raciais e para o Ensino de História e Cultura Afro-Brasileira e Africana. Brasília, 2004. Disponível em: https://www.uel.br/projetos/leafro/pages/arquivos/DCN-s\%20\%20Educacao\%20das\%20Relacoes\%20Etnico-Raciais.pdf. Acesso em: 19 jul. 2021.

BRASIL. Ministério da Educação. Base Nacional Comum Curricular. Brasília, DF: Ministério da Educação, 2017. http://basenacionalcomum.mec.gov.br/images/BNCC_EI_EF_110518_versaofinal_site.pdf. Acesso em: 27 
jun. 2018.

BRASIL. Ministério da Educação. Conselho Nacional de Educação. Resolução no 4, de 17 de dezembro de 2018. Institui a Base Nacional Comum Curricular na Etapa do Ensino Médio (BNCC-EM) [...]. Brasília, DF: O Presidente do Conselho Nacional de Educação, 2018. Disponível em: http://portal.mec.gov.br/index.php?option=com_docman\&view=download\&alias=104101-rcp00418\&category_slug=dezembro-2018-pdf\&Itemid=30192. Acesso em: 19 jul. 2021.

BRASIL. Decreto no 8.727, de 28 de abril de 2016. Dispõe sobre o uso do nome social e o reconhecimento da identidade de gênero de pessoas travestis e transexuais no âmbito da administração pública federal direta, autárquica e fundacional. Brasília, DF: Presidência da República, 2016. Disponível em: http://www.planalto.gov.br/ccivil_03/_ato2015-2018/2016/decreto/d8727.htm. Acesso em: 19 jul. 2021.

BRANDÃO, Rebeca Silva; MENDONÇA, Rosa Helena; PAPINI, Rossana. Memórias de professoras: tecendo cineconversas com "O incrível exército de Brancaleone". Revista Brasileira de Pesquisa (Auto)Biográfica - Edição Especial, Salvador/BA, v. 05, n. 16, p. 1577-1594, 2020.

CERTEAU, Michel de. A invenção do cotidiano - artes de fazer. Petrópolis: Vozes, 2008.

DOMINGUES, Petrônio. Movimento negro brasileiro: alguns apontamentos históricos. Revista Tempo, [s. 1.], V. 12, n. 23, p. 100-122, 2007.

EVARISTO, Conceição. Insubmissas lágrimas de mulheres. Rio de Janeiro, Malê, 2016.

EVARISTO, Conceição. Poemas da recordação e outros movimentos. Rio de Janeiro: Pallas, 2017.

SOTERO, Elaine; CORREA, Marco Aurélio; COUTINHO, Brenda. A quem seu racismo atinge? Questão racial e pandemia no Brasil. Educação \& Imagem, Rio de Janeiro, v.7, n.p 2020. Disponível em: http://www.labeduimagem.pro.br/jornais/ed_img/ anteriores/ ano7_ed35/img_brasil_art2_1.html Acesso em: 08 set. 2021.

FREIRE, Paulo. Pedagogia da autonomia: saberes necessários à prática educativa. São Paulo: Paz e Terra, 2009.

FREIRE, Paulo. Pedagogia do Oprimido. 58. ed. São Paulo: Paz e Terra, 2014a.

FREIRE, Paulo. Pedagogia da indignação: cartas pedagógicas e outros escritos: São Paulo: Paz e Terra, 2014b.

GOMES, Nilma Lino. Educação, identidade negra e formação de professores/as: um olhar sobre o corpo negro e o cabelo crespo. Educação e Pesquisa, São Paulo, v. 29, n. 167-182, jan./jun. 2003.

GOMES, Nilma Lino. Indagações sobre currículo: diversidade e currículo / [Nilma Lino Gomes]; organização do documento Jeanete Beauchamp, Sandra Denise Pagel, Aricélia Ribeiro do Nascimento. Brasília: Ministério da Educação, Secretaria de Educação Básica, 2007. 48 p.

GOMES, Nilma Lino. Diversidade étnico-racial, inclusão e equidade na educação brasileira: desafios, políticas e práticas. RBPAE, [s. 1.], v. 27, n. 1, p. 109-121, jan./abr. 2011.

GOMES, Nilma Lino. Movimento negro e educação: ressignificando e politizando a raça. Educ. Soc., Campinas, v. 33, n. 120, p. 727-744, jul./set. 2012. Disponível em http://www.cedes.unicamp.br. Acesso em: 19 jul. 2021.

GONÇALVES, Luiz Alberto; SILVA, Petronilha Beatriz Gonçalves. Movimento negro e educação. Revista Brasileira de Educação, São Paulo, Autores Associados, ANPED, n. 15, p. 134-158, 2000.

HOOKS, bell. O feminismo é para todo mundo: políticas arrebatadoras. $4^{\mathrm{a}}$ ed. Rio de Janeiro: Rosa dos Tempos, 2019.

LOBO, Thamy. Nós 'escritoresleitores': tecendo narrativas cotidianas e imaginárias com jovens acerca de movimentos migratórios. 2021. 138 f. Dissertação (Mestrado em Educação - Processos Formativos e Desigualdades Sociais) - Faculdade de Formação de Professores, Universidade do Estado do Rio de Janeiro, São Gonçalo, 2021.

MACHADO, Marcelo Ferreira; MORAIS, Maria; TOJA, Noale. 'Cineconversas' - criando currículos com 
filmes de migração. Revista de la Escuela de Ciencias de la Educación, Mendoza/AR, v. 1, n. 15, año 16, p. 93-103, enero/jun. 2020.

MATURANA, Humberto. A ontologia da realidade. Belo Horizonte: UFMG, 1999.

MATURANA, Humberto. Cognição, ciência e vida cotidiana. Belo Horizonte: UFMG, 2006.

MENDONÇA, Rosa Helena de; SANTOS, Joana Ribeiro dos; TOJA, Noale; MORAIS, Maria. "Cineconversas" e fabulações curriculantes: o uso de filmes e a potência das conversas como metodologia de pesquisa em Educação. Revista e-Curriculum, São Paulo, Programa de Pós-graduação em Educação: Currículo - PUC/SP, v. 18, n. 4, p. 1109-1130, out./dez. 2020.

MINISTÉRIO DA SAÚDE, 2021. Disponível em: emfile://C:/Users/renata/Downloads /Plano\%20Nacional\%20de\%20Operacionaliza\%C3\%A7\%C3\%A3o\%20da\%20Vacina\%C3\%A7\%C3\%A $30 \% 20$ contra $\% 20$ a\% 20Covid-19\%20-\%20PNO\%20-\%2011\%C2\%AA\%20Edi \% C3\%A7\%C3\%A3o.pdf. Acesso em: 07 dez. 2021.

OLIVEIRA, Inês Barbosa de. O currículo como criação cotidiana. Petrópolis, RJ: DP et Alii; Rio de Janeiro: FAPERJ, 2012.

PELA INTERNET 2. [Compositor e intérprete]: Gilberto Gil. [S. 1.]: Geléia Geral, 2018. (4min 21s).

PODCAST ERER Ufes. Disponível em: https://open.spotify.com/episode/6KUJr6rF5RNMsqDwVNBwju. Acesso em: 06 ago. 2021.

RAMOS, Andreia Teixeira. Narrativas autobiográficas de uma mulher negra: identidades sociais de raça e gênero. Travessias, Cascavel, v. 13, n. 3, p. 15-34, set./dez. 2019. Disponível em: http://www.unioeste.br/travessias. Acesso em: 17 de mar. de 2020.

RAMOS, Andreia Teixeira. Marielle Franco, a potência da insubmissão!. Sul-Sul - Revista de Ciências Humanas e Sociais, [S. 1.], v. 1, n. Especial, p. 35-52, 2021a. DOI: 10.53282/sulsul.v1iEspecial.835. Disponível em: https://revistas.ufob.edu.br/index.php/revistasul-sul/article/view/835. Acesso em: $8 \mathrm{dez}$. 2021.

RAMOS, Andreia Teixeira. Geografia dos afetos - cartas, cartões postais, diário de campo e caderno de uma pesquisadora. Vitória: Pedregulho, 2021. 196 p. Disponível em: https://www.editorapedregulho.com.br/downloads. Acesso em: 6 jul. $2021 \mathrm{~b}$.

RAMOS, Andreia Teixeira; GONZALEZ, Soler. Práticas pedagógicas dialógicas como possibilidade de criação de currículos nos cotidianos escolares. Revista Espaço do Currículo, v. 13, p. 583-591, 2020.

ROCHA, Renata; LOBO, Thamy. Bricolagens artísticas: contradições e (in)conformidades na arte e na educação carioca. Revista Teias - Seção Temática Docência, currículo, didática, aula: fantástico arquivo político da diferença, Rio de Janeiro: ProPed/UERJ, v. 21, n. 63, p. 309-323, out./dez. 2020.

ROCHA, Renata. 'Vendouvindosentindopensando' com as paisagens em deslocamento: migrações, currículos e 'cineconversas'. 2021. Dissertação (Mestrado em Educação) -Faculdade de Formação de Professores, Universidade do Estado do Rio de Janeiro, São Gonçalo, 2021.

ROMÃO, Jeruse (org.). História da educação dos negros e outras histórias. Brasília: MEC/Secad, 2005.

SOARES, Conceição; SANTOS, Edméa. Artefatos tecnoculturais nos processos pedagógicos: usos e implicações para os currículos. In: ALVES, Nilda; LIBÂNEO, José Carlos. Temas de Pedagogia: diálogos entre didática e currículo. São Paulo: Cortez, 2012. p. 308-330.

\section{Correspondência}

Andreia Teixeira Ramos: Professora do curso de Licenciatura Intercultural Indígena (Prolind) da Universidade Federal do Espírito Santo. Mestra em educação pelo Programa de Pós-Graduação em Educação da Universidade Federal do Espírito Santo (2011-2013/CAPES). Doutora em educação pelo 
Programa de Pós-Graduação em Educação da Universidade de Sorocaba (2015-2018/CAPES). Líder do Grupo de Pesquisa "Territórios de Aprendizagens autopoiéticas" (CNPq) e do Projeto de ensino, pesquisa e extensão "Narradores da Maré" do Centro de Educação da Universidade Federal do Espírito Santo. Pesquisadora do Grupo de pesquisa (CNPq) "Ecologias do Narrar" da Universidade Federal do Rio de Janeiro (UFRJ). Pesquisadora pós-doc do Grupo de Pesquisa (CNPq) "Currículos cotidianos, redes educativas, imagens e sons" do Programa de Pós-Graduação em Educação (Proped) da Faculdade de Educação da Universidade do Estado do Rio de Janeiro. Membra do Grupo de Trabalho de Educação Ambiental (GT22) da Associação Nacional de Pós-Graduação (ANPEd) e Pesquisa em Educação e da Associação Brasileira do Currículo (ABdC).

E-mail: andreiatramos.ea@gmail.com

Renata Rocha: Orientadora Pedagógica e Educacional nos municípios (Magé/RJ) e (Japeri/RJ). Mestra em Educação pelo (PpgEdu/UERJ). Especialista em Ensino de Histórias e Culturas Africanas e Afrobrasileira pelo IFRJ e Pedagoga pela (FFP/UERJ). Membra do Grupo de Pesquisa Currículos Cotidianos: redes educativas, imagens e sons (Proped/UERJ). Bolsista CAPES (2020-2021). Membra da Associação Brasileira do Currículo (ABdC).

E-mail: renatarochaoliveira87@gmail.com

Elaine Sotero: Graduada em Pedagogia pela Universidade do Estado do Rio de Janeiro - (2018). Mestranda em Educação pelo Programa de Pós Graduação - ProPED/UERJ - com bolsa CAPES/CNpq (2020-2022). Membra do Grupo de Pesquisa Currículos Cotidianos: redes educativas, imagens e sons (Proped/UERJ). Membra da Associação Brasileira do Currículo (ABdC).

E-mail: elainesotero2@gmail.com

Texto publicado em Currículo sem Fronteiras com autorização dos autores. 